\title{
Contribuições epistemológicas/metodológicas para o fortalecimento de uma (cons)ciência emancipadora
}

\author{
Epistemological/methodological contributions \\ to the fortification of an emancipatory con(science)
}

Marcelo José Monteiro Ferreira ${ }^{1}$

Raquel Maria Rigotto ${ }^{1}$

${ }^{1}$ Departamento de Saúde Comunitária, Centro de Ciências da Saúde, Universidade Federal do Ceará. R. Prof. Costa Mendes $1608 / 5^{\circ}$ andar, Rodolfo Teófilo. 60.431970 Fortaleza CE Brasil. marceloferreira@ufc.br

\begin{abstract}
This article conducts a critical and reflective analysis into the paths of elaboration, sistematization and communication of the results of research in conjunction with colleges, social movements and individuals in the territory under scrutiny. For this, the article embraces as the core analytical theme the process of shared production of knowledge, both in the epistemological-methodological field and with respect to its social destination. The case study was adopted as the methodology, preceded by the use of focused groups and in-depth interviews as technique. To analyze the qualitative material discourse analysis was adopted in line with the assumptions of in-depth hermeneutics. The results are presented in two stages: Firstly, the new possibilities for a paradigmatic reorientation are discussed from the permanent and procedural interlocution with the empirical field and it's different contexts and authors. Secondly, it analyzes in the praxiological dimension, the distinct ways of appropriation of knowledge produced in dialogue with the social movements and the individuals in the territory under scrutiny. It concludes by highlighting alternative and innovative paths to an edifying academic practice. which stresses solidarity and is sensitive to the vulnerable population and its requests.
\end{abstract}

Key words Epistemology, Social participation, Empowerment, Health communication
Resumo Opresente artigo tem como objetivo realizar uma análise reflexiva-crítica acerca da trajetória de elaboração, sistematização e comunicação dos resultados de uma pesquisa desenvolvida em parceria com universidades, movimentos sociais e sujeitos dos territórios estudados. Para tanto, adota como eixo condutor analítico o processo de produção compartilhada de conhecimentos, tanto no âmbito epistêmico-metodológico como em relação à sua destinação social. Como metodologia, adotou-se o Estudo de Caso, precedido do uso de grupos focais e entrevistas em profundidade como técnicas. Para a análise do material qualitativo, adotou-se a Análise de Discurso em conformidade com os pressupostos da Hermenêutica de Profundidade. Os resultados são apresentados em dois momentos. No primeiro, discutem-se novas possibilidades para uma reorientação paradigmática a partir de uma interlocução permanente e processual com o campo empírico e seus diferentes contextos e atores. No segundo, analisa na dimensão praxiológica as distintas formas de apropriação do conhecimento produzido em diálogo com movimentos sociais e sujeitos dos territórios estudados. Conclui apontando caminhos alternativos e inovadores para uma prática acadêmica edificante, solidária e sensivel às demandas das populações mais vulneráveis.

Palavras-chave Epistemologia, Participação social, Empoderamento, Comunicação em saúde 


\section{Introdução}

Ciência, capitalismo e conflitos socioambientais: tecendo as mediações necessárias

O presente artigo tem como objetivo realizar uma análise reflexiva-crítica acerca da trajetória de elaboração, sistematização e comunicação dos resultados de uma pesquisa desenvolvida em parceria com universidades, movimentos sociais e sujeitos dos territórios estudados. Para tanto, adota como eixo condutor analítico o processo de produção compartilhada de conhecimentos, tanto no âmbito epistêmico-metodológico como em relação à sua destinação social. Nesse sentido, problematiza o papel da Ciência Moderna, discutindo caminhos alternativos para a tessitura de novos saberes e práticas, apropriados e utilizados como ferramenta de lutas e promotoras de equidade e justiça socioambiental.

No bojo da atual conjuntura social, o paradigma moderno de ciência (re)produz e amplifica as desigualdades cognitivas e sociais entre países centrais e periféricos. Esse modelo apresenta como principais características, a ruptura epistemológica com o senso comum e com os saberes tradicionais, promovendo uma relação hierarquizada entre conhecimento e poder; além de reforçar a mediação da Ciência e da Tecnologia como contributos para a expansão do padrão de dominação e acumulação do capital ${ }^{1,2}$.

A ciência progressivamente se transformou na força produtiva, por excelência, do capitalismo, acentuando as contradições na sociedade, repercutindo nas condições de vida e de saúde, principalmente das populações mais vulneráveis. O paradigma positivista que se consolidou como um instrumento de manipulação da natureza em benefício de um sistema produtivo excludente e de uma ordem social segregadora, apresenta no interior de sua essência incongruências estruturais, denunciando sua incapacidade de oferecer respostas aos problemas contemporâneos.

A história é generosa em nos demonstrar exemplos onde o desenvolvimento científico e tecnológico, em meio aos seus avanços inquestionáveis, deixou irresolutas questões básicas como a fome e a pobreza de milhares de pessoas. Apesar de dispormos de tecnologia suficiente para solucionar problemas de saúde pública como doenças diarreicas e parasitárias, nos países localizados na periferia do capitalismo ainda persistem quadros graves de desnutrição e mortalidade infantil, provindas, em grande medida, pela falta de saneamento básico e de água potável.
De acordo com Miranda ${ }^{3}$, cerca de 2,6 bilhões de pessoas não possuem saneamento básico e mais de 1,1 bilhão não tem acesso a quantidade mínima de água potável. Nesse quesito, pesquisa ${ }^{4}$ demonstra que no continente africano, menos de $50 \%$ das pessoas dispõem de água própria para consumo humano.

Desde a década de 1980 até os dias atuais, a alimentação disponível nos países em desenvolvimento reduziu em $30 \%{ }^{5}$. Entre os que passam fome no mundo, " $50 \%$ são proprietários rurais, $20 \%$ são camponeses sem terra e $10 \%$ pastores, pescadores e povos da floresta"4. A expansão do agronegócio nos países latino-americanos demonstra a conformação de um arcabouço conjuntural de mecanismos políticos, jurídicos e tecnológicos que configuram a perda de soberania, de privatização das riquezas naturais, bem como a apropriação e, muitas vezes, invasão de terras públicas por empresas privadas ${ }^{6}$, amparadas pelo slogan do desenvolvimento. Dessa forma, países como o Brasil se subordinam ao mercado internacional como produtores de commodities à custa das intoxicações humanas por agrotóxicos, principalmente dos trabalhadores e famílias rurais, da substituição da fauna e flora nativa em detrimento da expansão dos monocultivos, além da contaminação da água e dos solos ${ }^{7}$.

Situação semelhante ocorre na região do semiárido cearense, mais precisamente no baixo Vale do Jaguaribe, localizado próximo à fronteira do Ceará com o Rio Grande do Norte. A partir dos anos 1980 a região registra a chegada de grandes empresas transnacionais e regionais de fruticultura irrigada para exportação, introduzindo um processo de desterritorialização, marcado por profundas transformações as quais repercutem diretamente sobre o perfil de morbimortalidade, bem como sobre as condições ambientais e de trabalho das populações ${ }^{8}$.

Durante a trajetória da pesquisa analisada neste manuscrito, intitulada de "Estudo epidemiológico da população do baixo Jaguaribe exposta a contaminação ambiental em área de uso de agrotóxicos" realizada no período de 2007 a 2011, evidenciou, dentre outros, que $97 \%$ dos trabalhadores do agronegócio e dos agricultores familiares estudados estavam expostos aos agrotóxicos. Tal exposição envolvia a presença de 4 a 30 ingredientes ativos distintos, distribuídos entre inseticidas, herbicidas e fungicidas. No conjunto dos dados foi possível identificar a presença de 25 grupos químicos distintos, dos quais $68,5 \%$ são classificados como extremamente tóxicos ou muito tóxicos ${ }^{8,9}$.

A partir da conjunção dos fatores apresentados, corroboramos com autores ${ }^{10}$ quando afir- 
mam que a Ciência Moderna hoje lida com incertezas e desconfianças materializadas em conflitos ambientais de escala global e local. Desse modo, trilhamos um caminho do conhecimento que construiu dilemas incapazes de serem resolvidos à luz do pensamento simplificador das ciências nomológicas.

A crise do paradigma moderno de ciência nos motiva a percorrer novos rumos na produção do conhecimento. Neste sentido, assume-se aqui o desafio de apresentar uma experiência em que o saber popular e tradicional agrega-se ao científico; em que os objetos de cunho teórico são transpassados pelas demandas sociais e apropriados pelos sujeitos históricos que participam da produção do conhecimento, ao tempo em que dele se nutrem e o multiplicam; comprometidos assim, não apenas com a produção acadêmica, mas, sobretudo, com a emancipação humana e social.

\section{Delineamento metodológico}

O presente artigo inscreve-se na fronteira entre os campos da Saúde Coletiva, das Ciências Sociais e Humanas e da Filosofia por estas assumirem posições privilegiadas para a análise do objeto de investigação em questão. Ainda, filia-se ao enfoque qualitativo, tendo em vista a natureza das análises que seguirão.

Como metodologia adotamos o Estudo de Caso. Esteban ${ }^{11}$ identifica três classificações de Estudo de Caso: o Instrumental, o Coletivo e o Intrínseco, sendo este último o que melhor se aplica aos objetivos dessa pesquisa por:

[...] alcançar uma maior compreensão de um caso em particular. Não se seleciona o caso porque representa a outros ou porque represente um aspecto ou problema em particular, mas porque o caso em si mesmo é o que nos interessa.

Dessa forma, assumimos como o Caso Intrínseco a ser analisado neste manuscrito, a trajetória da pesquisa "Estudo epidemiológico da população do baixo Jaguaribe exposta a contaminação ambiental em área de uso de agrotóxicos", a qual foi aprovada pelo Comitê de Ética em Pesquisa da Escola de Saúde Pública do Ceará. Dentre as particularidades contidas neste estudo, contributivas para a sua escolha enquanto objeto de investigação, destacamos: o envolvimento de seis Instituições de Ensino Superior - Núcleo TRAMAS da Universidade Federal do Ceará, Instituto Federal de Educação, Ciência e Tecnologia (IFCE), Faculdade de Filosofia Dom Aureliano Matos - FAFIDAM/UECE, Grupo de Estudos de Saúde do Trabalhador Rural (GESTRU), da Universidade Federal de Minas Gerais, a Universidade de Brasília (UnB) e o Centro de Pesquisas Aggeu Magalhães (CPqAM)/Fiocruz de Pernambuco; a produção sistemática e compartilhada de conhecimentos junto a movimentos sociais como o Movimento dos Trabalhadores Rurais Sem Terra (MST), Cáritas Diocesana de Limoeiro do Norte, Central Sindical e Popular Conlutas (CSP Conlutas); o envolvimento ativo das comunidades locais pesquisadas enquanto protagonistas na apropriação dos resultados obtidos pelas pesquisas, subsidiando suas reivindicações a partir da fundamentação científica produzida em conjunto.

Como técnica, utilizamos o Grupo Focal, tendo em vista que este é o melhor instrumento para captar, a partir das trocas realizadas no grupo, conceitos, sentimentos, atitudes, crenças, experiências e reações ${ }^{12}$. Quanto ao número, a autora $^{12}$ aconselha a realizar em torno de cinco para posterior avaliação da qualidade do material reunido. Contudo, o campo empírico impôs limitações que impediram de atingir esse quantitativo, restando-nos a realização de quatro encontros. Quanto aos integrantes, fizeram parte representantes das seguintes instituições e movimentos sociais: Pastorais Sociais da diocese e Cáritas Diocesana de Limoeiro do Norte, CSP Conlutas, Movimento dos Trabalhadores Rurais Sem Terra (MST), professores da FAFIDAM e Núcleo TRAMAS, perfazendo assim, uma média de nove participantes.

Após uma análise criteriosa do material qualitativo oriundo dos grupos focais, identificamos lacunas que nos conduziram novamente a campo no intuito de elucidar questões consideradas essenciais para a boa execução da presente pesquisa. Para tal, recorremos à utilização de entrevistas não estruturadas, devido à qualidade do material produzido nestes encontros ser mais densa e ter um grau de profundidade incomparável ${ }^{13}$. Realizamos assim um total de quatro entrevistas junto aos seguintes sujeitos: representante da Diocese de Limoeiro do Norte, da CSP Conlutas, do Ministério Público Estadual e professor da FAFIDAM. Essa iniciativa nos proporcionou um contato mais acurado com os fenômenos subjetivos, bem como uma compreensão mais aprofundada acerca dos papeis sociais assumidos pelos indivíduos, suas atitudes coletivas e símbolos sociais. $\mathrm{O}$ critério adotado para a escolha dos entrevistados deu-se, fundamentalmente, pelo envolvimento político e/ou institucional com as questões relacionadas ao tema desta pesquisa. 
Para a interpretação do material qualitativo utilizamos a Hermenêutica de Profundidade (HP). A escolha deste referencial teórico deveu-se ao fato de adentrarmos na seara da linguagem, no universo dos significados cujos produtos são pré-interpretados por sujeitos que estão inseridos em um contexto sócio-histórico ${ }^{14}$. Neste sentido, a HP tem se mostrado um importante instrumento para melhor compreender as inter-relações entre o mundo simbólico e o plano material em que estas se desenham no bojo da sociedade capitalista ${ }^{15}$. Para a análise do material qualitativo, adotamos a Análise de Discurso (AD), pois procura "descrever, explicar e avaliar criticamente os processos de produção, circulação e consumo dos sentidos"16.

O presente estudo foi elaborado em consonância com os parâmetros contidos na Resolução 196/96 ${ }^{17}$ do Conselho Nacional de Saúde (CSN), vigente à época, já que se trata de pesquisa envolvendo a participação de seres humanos. Esta, por sua vez, foi submetida e aprovada após avaliação do Comitê de Ética na Pesquisa (CEP) da Universidade Federal do Ceará.

\section{Resultados e discussão}

\section{Entre epistemes e métodos: construindo possibilidades para uma reorientação paradigmática}

Durante as visitas exploratórias da pesquisa "Estudo epidemiológico da população do baixo Jaguaribe exposta a contaminação ambiental em área de uso de agrotóxicos", identificou-se no território, situações, contextos e conjunturas que desafiavam constantemente a elaboração de um delineamento metodológico capaz de captar suas diferentes nuanças: empresas transnacionais promovendo uma reordenação do território, expropriando e impondo aos camponeses uma nova relação trabalhista, acompanhada de riscos ocupacionais diversos; pequenos agricultores que se subdividiam em proprietários de terras dentro e fora dos perímetros irrigados, com todas as particularidades de cada um dos contextos, desenvolvendo relações variadas de produção em regime de "parceria" com as grandes empresas; agricultores familiares e assentados da reforma agrária buscando efetivar uma transição agroecológica em meio ao cerco do agronegócio ${ }^{8,18}$.

Após o reconhecimento dos distintos cenários presentes no território do baixo Jaguaribe, por meio de sucessivas incursões em campo, a proposta inicial de se realizar um estudo epidemiológico desdobrou-se em quatro grandes eixos da pesquisa: caracterização do contexto de exposição humana aos agrotóxicos; caracterização ambiental e avaliação da contaminação aérea por agrotóxicos; caracterização da exposição humana e dos agravos à saúde relacionáveis aos agrotóxicos; alternativas ao desenvolvimento de políticas públicas?.

Um fator determinante para se chegar a esse delineamento de estudos foi o contato permanente e sistemático junto aos movimentos sociais que atuam na região como o MST e a CPT, tornando possível a aproximação, sempre processual, com o objeto de estudo:

A pesquisa não chegou com um objeto pronto. Ela tinha um título 'Estudo epidemiológico', mas foi uma pesquisa que foi sendo construída ao longo do tempo. Podemos garantir isso! Desde o começo a participação e toda a preocupação permanente de ouvir os movimentos sociais, sempre sentar, sempre perguntar, sempre pedir propostas (GF).

Mediante as complexidades apresentadas pelo campo empírico, tornava-se claro que somente a epidemiologia stricto sensu não seria suficiente para apreender as diferentes situações de riscos e vulnerabilidades presentes na configuração sócio-histórica do baixo Jaguaribe. O movimento dialético estabelecido junto aos sujeitos dos territórios de investigação possibilitou caracterizar a multidimensionalidade do objeto ora referido, requerendo, por sua vez, a triangulação de processos metodológicos atributivos e formais, de "raciocínios socioeconômicos e antropológicos e de recursos das ciências sociais ligados aos das ciências biológicas"19.

Dessa forma, fez-se necessária a adoção de um modelo investigativo que permitisse o diálogo com o risco, sem desvinculá-lo de seu contexto histórico, econômico, político, ambiental, cultural e sanitário. A especificidade do objeto exigiu também a adequação a uma pluralidade metodológica, tendo em vista que "cada método é uma linguagem e a realidade responde na língua em que é perguntada" ${ }^{\prime 20}$.

Em uma perspectiva crítica, não existe conhecimento sem práticas e atores sociais. Afinal, "o problema de estudo é vivido por eles; eles detêm conhecimentos especiais e insubstituíveis; a eles caberá apropriar-se do processo e dos resultados como esperamos, ferramentas de transformação e emancipação"21. Dessa forma, ao dialogar com diferentes abordagens metodológicas e atores sociais durante a produção do conhecimento, o grupo de pesquisadores estava indo ao encon- 
tro das orientações oferecidas por Bourdieu, para quem "a pesquisa é demasiado difícil para se tomar a liberdade de confundir rigidez, que é o contrário da inteligência e da invenção, com o rigor" ${ }^{22}$.

Neste sentido, buscou-se facilitar a construção de espaços em que o saber científico dialogasse com o saber popular e com o saber camponês de forma horizontal e fraterna. Mais que isso, ao refutar a falsa neutralidade científica que promove o distanciamento do sujeito que pesquisa com o objeto pesquisado, assumia-se um compromisso ético-político de desenvolver uma ciência "herética" 22. Tal situação converge para o conhecimento-emancipação que privilegia o próximo enquanto forma de conceber e compreender o real. Implica, pois, transformar a solidariedade também numa forma de saber e agir, capaz de aproximar realidades cerceadas pela ciência moderna 5 .

Esse processo de trabalho, em que sujeitos pesquisados passam a figurar também como pesquisadores, pode ser identificado na Pesquisa Participativa Baseada nas Comunidades (CBPR). Dentre o seu vasto escopo de abrangência, destacamos algumas características que estiveram presentes na pesquisa "Estudo epidemiológico da população da região do baixo Jaguaribe exposta à contaminação ambiental em área de uso de agrotóxicos", tais como: "participação social; cooperação, engajamento de membros de comunidades e pesquisadores num processo conjunto no qual cada um contribui igualmente; aprendizado mútuo; desenvolvimento de sistemas de captação local; empoderamento por meio do qual os participantes podem aumentar o controle sobre suas vidas; equilíbrio entre pesquisa e ação" ${ }^{23}$.

$\mathrm{Na}$ CBPR, a comunidade se envolve na elaboração de uma agenda comum para a pesquisa, discutindo e deliberando conjuntamente como seus resultados serão apropriados pelos diferentes atores. Nessa perspectiva, existe uma distribuição horizontal de poderes, onde todos os participantes possuem voz legítima nos diferentes estágios de tomada de decisão ${ }^{24}$. Fischer ${ }^{25}$ ressalta ainda a horizontalidade dessas relações ao enfatizar que na CBPR os “cientistas profissionais” não devem deter quaisquer privilégios em relação aos "cientistas cidadãos".

Dessa forma, consubstancia-se a opção por um novo modelo de racionalidade que longe de negar o saber científico, buscou "fazer um uso contra-hegemônico da ciência hegemônica"26. Assemelha-se, portanto, a ecologia de saberes, entendida como:
A criação de uma nova forma de relacionamento entre o conhecimento científico e as demais formas de conhecimento, visando à construção de uma sociedade mais justa e democrática, bem como de uma sociedade mais equilibrada em suas relações com a natureza ${ }^{27}$.

A ecologia de saberes assume a forma epistemológica das lutas sociais no momento em que dá voz à diversidade de experiências de resistência, auxiliando na criação de novas maneiras de relacionamento entre o conhecimento científico e as diferentes manifestações de saber. Assente no desejo de contribuir com a reorientação das práticas acadêmicas, busca produzir um saber solidário que "é o conhecimento obtido no processo, sempre inacabado, de nos tornarmos capazes de reciprocidade através da construção e do reconhecimento da intersubjetividade" ${ }^{5}$.

Essas características presentes na ecologia de saberes são também identificadas sob a ótica da Justiça Ambiental. A forma como cientistas respeitam solidariamente as populações atingidas em suas demandas, autonomia e protagonismos diante dos conflitos socioambientais contribuem para a conformação de laços de confiança constituintes das comunidades ampliadas de práticas que, durante certo período, produzem de forma compartilhada conhecimentos e planejam ações conjuntamente ${ }^{23}$.

\section{A função social da ciência e sua apropriação pelos sujeitos dos territórios}

A ampliação do trabalho articulado entre pesquisadores e movimentos sociais durante a trajetória da pesquisa "Estudo epidemiológico da população do baixo Jaguaribe exposta a contaminação ambiental em área de uso de agrotóxicos" culminou com o surgimento do Movimento 21, ou M21. Este, por sua vez, é formado por um conjunto de atores provenientes de diferentes instituições como Cáritas de Limoeiro do Norte, professores da FAFIDAM, pesquisadores do Núcleo TRAMAS, integrantes do MST, das pastorais sociais da diocese de Limoeiro do Norte e da Central Sindical Popular Conlutas (CSP Conlutas).

Importante salientar que muitos integrantes do M21 já possuíam um histórico de atuação política contra a expansão do agronegócio na região do baixo Jaguaribe ainda na década de 1990. Contudo, suas intervenções passaram a ser individualizadas com o passar do tempo. Por meio da pesquisa referida, esses sujeitos enxergaram a oportunidade de se rearticularem, fortalecendo novamente suas alianças e potencializando suas ações: 
A contribuição da pesquisa foi em agregar esses movimentos que estavam divididos há certo tempo, por falta mesmo de maturidade ou por falta de uma sensibilidade em dizer que o projeto individual de cada organização não poderia ser um limite para que a gente avançasse em outras lutas comuns (G.F).

O potencial contra-hegemônico dos movimentos sociais reside na sua capacidade de articulação e organização com outros atores, que por vezes apresentam posicionamentos políticos divergentes em algum momento de suas lutas. Nesse sentido, faz-se necessário "esclarecer o que une e o que separa os diferentes movimentos em suas diferentes práticas, de modo a determinar as possibilidades e os limites da articulação ou integração entre eles" ${ }^{\prime 2}$.

Somente através da inteligibilidade recíproca é possível construir alianças e ampliar as possibilidades de intervenções conjuntas. Dentre estas, o M21 adotou como uma de suas estratégias, a divulgação dos passivos socioambientais decorrentes do agronegócio para a sociedade local, fundamentando-se nos resultados obtidos através da pesquisa supracitada. Dessa forma, a prática acadêmica ganha considerável relevância também por articular conjuntamente produção científica, mobilização social e processos comunicativos.

Importante salientar que ao tratarmos de processos comunicativos, distanciamo-nos de um conjunto de teorias e práticas meramente explicativas, prescritivas ou verticalizadas. Por outro lado, referimo-nos a um esforço de problematizar a realidade a partir de situações concretas, de modo que a ação comunicativa possa contribuir para uma reflexão transformadora ${ }^{28}$.

Em cada um dos eixos que compuseram a pesquisa, estava presente o compromisso de democratizar os seus resultados aos territórios estudados e seus sujeitos, em um processo dinâmico e sistemático. Desse modo, o esforço para se efetivar a publicização das informações produzidas contribuiu significativamente para o envolvimento da sociedade, proporcionando mais autonomia na defesa dos seus direitos:

A pesquisa é incisiva no sentido que dá voz ao povo, da maioria que sofre as consequências desse modelo de desenvolvimento. Ela empodera os trabalhadores e contribui para que nós, que somos dos movimentos sociais, que a gente pudesse se apropriar de muitos desses saberes (GF).

O direito à informação é parte integrante do direito à saúde. Contudo, em nossa sociedade concentradora, centraliza-se a política, a economia, acumula-se o capital, a cultura e também a palavra. Com isso, o direito de falar e de ser ouvido é desigualmente distribuído. Como forma de contraposição, o grupo de pesquisadores, juntamente com o M21, buscou descentralizar as informações, estimulando a criação de espaços alternativos de expressão e divulgação de conteúdos $^{29}$. Esse movimento coaduna-se às tradições da Medicina Social Latino-americana ao tempo em que amplia e politiza o debate sobre a saúde enquanto expressão de direito e cidadania, conforme expresso na Constituição Federal e na Lei Orgânica da Saúde ${ }^{30,31}$.

Dentre as estratégias de socialização do conhecimento consideradas inovadoras pelos pesquisadores e o M21, destacam-se a realização de seminários públicos nos próprios locais estudados. O primeiro deles, intitulado de "Agrotóxicos no Vale: novos ares e desafios para a atuação pública", foi realizado em agosto de 2008 e elaborado em conjunto com o Ministério Público Estadual, a Diocese e a Cáritas de Limoeiro do Norte, o Núcleo TRAMAS (Trabalho, meio ambiente e saúde para a sustentabilidade), a $10^{\text {a }}$ Célula Regional de Saúde do Ceará, o Esplar, a Via Campesina e a Articulação do Grito dos Excluídos ${ }^{18}$.

No mesmo período, eclodiu a primeira greve na Del Monte Fresh Produce Ltda., na qual cerca de 1300 dos seus trabalhadores utilizaram o Seminário para expor suas reivindicações diante da representante do Ministério Público do Trabalho (MPT). Como um dos produtos, a Procuradora Regional do Trabalho determinou a readmissão de 197 grevistas $^{21}$.

A apropriação do Seminário enquanto espaço de denúncias contribuiu para a troca de experiências entre cientistas, trabalhadores e população, possibilitando formas fecundas de intercâmbio e aprendizagens, potencializando uma inteligência coletiva e solidária. Esta se configura enquanto uma estratégia importante para que as comunidades possam se apropriar de conhecimentos, somando sua articulação com a mobilização política. Como corolário, lutam para superar sua condição de grupos vulneráveis com vozes silenciadas tentando transformar suas realidades ${ }^{23}$.

Em 2009, outro seminário foi organizado pelos pesquisadores e o M21, denominado de "Jornada mundo rural, agrotóxicos e saúde", contando também com a participação de docentes de diferentes Instituições de Ensino Superior (IES), dentre eles, da Universidade Federal do Mato Grosso (UFMT). Na ocasião, foram apresentados os resultados de pesquisas desenvolvidas em Lucas do Rio Verde (MT), possibilitando a troca de 
experiências acerca da expansão do agronegócio em diferentes territórios no Brasil. Além disso, buscou-se alertar para a gravidade dos problemas relacionados à saúde, ao trabalho e ao ambiente decorrente da pulverização aérea praticada na Chapada do Apodi.

Identificamos aqui, a centralidade que assume a comunicação na medida em que contribui com a democratização das informações, possibilitando o compartilhamento de experiências de luta e resistência, além do desenvolvimento de protagonismos entre os atores locais. Auxilia também qualificando as intervenções desses sujeitos, ampliando o debate sobre o direito à saúde ${ }^{29}$.

Na mesma oportunidade foi realizada a "Oficina de mapeamento de vulnerabilidades socioambientais e contextos de promoção da saúde", que contou com a participação de mais de 40 pessoas provenientes de diferentes localidades ${ }^{8,9}$. A metodologia adotada nessa oficina fundamentou-se na utilização da Cartografia Social, permitindo às comunidades, simultaneamente, produzirem, problematizarem e se apropriarem das informações sobre seus territórios. Desse modo, a cartografia social assume o lugar em que "se estabelecem relações entre linguagens representacionais e práticas territoriais, entre a legitimidade dos sujeitos da representação cartográfica e seus efeitos de poder sobre o território" 32 .

Esse procedimento permitiu compartilhar os conhecimentos produzidos de maneira conjunta, além de reunir diferentes percepções e olhares sobre o mesmo território, conforme demonstra:

A ideia dos mapas, das comunidades construirem mapas sobre a sua visão, sobre o seu lugar, foi fantástica. Tanto é, que do começo ao fim da pesquisa, a cartografia social foi e é utilizada como referência que serve para as comunidades representarem a percepção do seu lugar (GF).

A cartografia social funcionou não só como ferramenta metodológica capaz de dar visibilidade aos conflitos nos territórios, mas também como instrumento que possibilitou a troca de experiências entre o conhecimento acadêmico e o popular. Aproxima-se, portanto, da ecologia de saberes, cujas práticas conduzem a uma nova orientação paradigmática, fundamentada no interconhecimento e pautada por valores éticos e políticos $^{27}$.

Ainda no ano de 2009 ocorreu o Grito dos Excluídos na Chapada do Apodi, tendo como lema "Tirem as mãos, a Chapada é nosso chão". Cerca de 5.000 pessoas entre moradores das comunidades, movimentos sociais e pesquisadores se reuniram nas ruas denunciando à sociedade os diversos problemas sociais e ambientais decorrentes do agronegócio na região. Dentre eles destacaram-se as que fizeram referência à contaminação do ar, do solo, das águas e dos alimentos, além do aumento do número de casos de intoxicação por agrotóxicos devido à utilização descontrolada dessas substâncias pelas empresas.

Esse processo de reivindicações envolvendo cientistas e população em denúncia sobre potenciais riscos de contaminação humana provocada pelo desequilíbrio no meio ambiente assemelhase ao ocorrido no caso Handford Downwinders. Impulsionadas pela preocupação de estarem expostas à radiação proveniente de testes com armas nucleares, comunidades do nordeste dos Estados Unidos uniram-se a pesquisadores e fundaram a Northwest Radiation Health Alliance, alertando a sociedade e o Estado sobre os perigos à saúde e ao ambiente decorrentes de radiações nucleares ${ }^{33}$.

Essa parceria entre pesquisadores e comunidades remonta a uma prática de pesquisa participativa e colaborativa, em que os diferentes sujeitos acordam de início que todos têm muito a aprender entre si, e aceitam trabalhar em conjunto a fim de aprenderem ainda mais. Tais práticas de produção compartilhada de conhecimentos assemelham-se às ideias contidas na Ciência Cidadã ou Militante, pois se fundamentam, principalmente, no saber das populações locais que vivenciam cotidianamente situações envolvendo conflitos socioambientais ${ }^{23,34}$.

Em 2010, o Núcleo TRAMAS juntamente com o M21, atendendo a solicitação dos movimentos sociais, promoveu o seminário denominado "Conhecimento e ação: resultados da pesquisa agrotóxicos/UFC". Nesse momento foi elaborado um dossiê contendo seis dos principais problemas identificados pela pesquisa e que apresentavam importantes impactos sobre a saúde pública e o ambiente, dentre eles, o resultado das análises que confirmaram a contaminação de águas superficiais e profundas por agrotóxicos. Todos os achados foram apresentados em audiências públicas na Câmara Municipal e na Assembleia Legislativa Estadual, culminando com a proibição da pulverização aérea no município 9 .

Diversas outras formas de comunicação dos resultados da pesquisa "Estudo epidemiológico da população do baixo Jaguaribe exposta a contaminação ambiental em área de uso de agrotóxicos" foram levadas a cabo pelos pesquisadores em parceria com o M21 e membros das comunidades. Dentre elas, destacamos: a elaboração de 10.000 exemplares de um cordel temático sobre 
a questão dos agrotóxicos no baixo Jaguaribe; a produção de um almanaque contendo jogos educativos e um DVD reunindo todas as produções acadêmicas no âmbito da pesquisa; além de um livro científico.

O conjunto de experiências elencadas até aqui nos permite afirmar que "a trajetória da pesquisa foi se articulando à trajetória das lutas populares e camponesas na região, ao emprestar o capital simbólico da Universidade e disponibilizar informações, cuja apropriação pelos movimentos sociais fortaleciam as ações em defesa da saúde e da vida"9.

Converge, portanto, para uma nova orientação paradigmática, contribuindo para a construção de uma ciência ética e comprometida com a destinação social do conhecimento que produz. Oferece, portanto, caminhos alternativos para o desenvolvimento de uma prática acadêmica edificante, solidária e sensível às demandas dos povos mais vulnerabilizados.

\section{Considerações finais}

A partir do exposto, analisamos situações em que a teoria deixou de figurar apenas no plano das ideias e passou a materializar-se na concretude das relações sociais, mediatizada pela ação das classes populares. Nesse sentido, merece relevância sua contribuição para a emancipação social, conforme defendido por Marx ${ }^{35}$ :

A arma crítica não pode, é claro, substituir a crítica da arma, o poder material tem de ser derru- bado pelo poder material, mas a teoria também se torna força material quando se apodera das massas.

Somente quando a teoria é apropriada, metabolizada e sintetizada em ato pelos sujeitos capazes de realizar as transformações sociais, têm-se de fato o uso social e democrático do conhecimento científico sendo posto a serviço da diminuição das desigualdades sociais. No bojo de todo esse trajeto, as diversas estratégias de produção, sistematização e comunicação dos resultados das pesquisas adquiriram importância fundamental no sentido de fortalecerem e qualificarem as reivindicações dos movimentos sociais e comunidades, transformando-se em instrumentos de resistência e luta pelas comunidades.

Soma-se, ainda, o valioso papel de mobilização, organização política e inserção nos territórios dos movimentos sociais apresentados aqui, contribuindo para que o tema do agronegócio em suas diferentes nuanças fossem pautados e debatidos pelos diversos veículos midiáticos. Por meio desse processo, construiu-se uma "ação coletiva, penetrando em vários níveis, nas relações familiares, comunitárias e societárias, no local e no nacional" ${ }^{\prime 36}$.

Destaca-se também a união entre pesquisadores e movimentos sociais buscando, a partir de uma realidade concreta, superar os limites epistemológicos e políticos de certas abordagens científicas que em nome da objetividade e neutralidade, desconsideram a complexidade dos fenômenos. "Isso desumaniza a prática científica frente ao sofrimento das populações e renega o princípio precaucionário"23.

\section{Colaboradores}

MJM Ferreira e RM Rigotto participaram igualmente de todas as etapas de elaboração do artigo. 


\section{Referências}

1. Santos BS. Introdução a uma ciência pós-moderna. $5^{\mathrm{a}}$ ed. Rio de Janeiro: Graal; 1989.

2. Oliveira M. Crise Ecológica e Sustentabilidade. In: Carvalho R, Costa G, organizadores. Nietzsche-Schopenhauer: ecologia cinza, natureza agônica. Fortaleza: EdUECE; 2013. p. 117-153.

3. Miranda AC. Reflexões acerca da situação e dos problemas referentes à crise socioambiental e seus reflexos à saúde humana: uma contribuição a partir do materialismo histórico e dialético [tese]. Rio de Janeiro: Escola Nacional de Saúde Pública Sérgio Arouca; 2012.

4. Freitas CM, Porto MFS. Saúde, ambiente e sustentabilidade. Rio de Janeiro: Editora Fiocruz; 2006.

5. Santos BS. A crítica da razão indolente: contra o desperdício da experiência. 7a ed. São Paulo: Cortez; 2009.

6. Freitas BMC. Marcas da modernização da agricultura do Perímetro Irrigado Jaguaribe-Apodi: uma face da atual reestruturação socioespacial do Ceará [dissertação]. Fortaleza: Universidade Estadual do Ceará; 2010.

7. Porto MF. Agrotóxicos, saúde coletiva e insustentabilidade: uma visão crítica da ecologia política. Cien Saude Colet 2007; 12(1):17-20.

8. Rigotto RM, organizador. Agrotóxicos, trabalho e saúde: vulnerabilidade e resistência no contexto da modernização agrícola no baixo Jaguaribe/CE. Fortaleza: Edições UFC; 2011

9. Rigotto RM, Carneiro FF, Pequeno AMC, Rocha MM, Ferreira MJM, Pessoa VM, Teixeira ACA, Silva MLV, Braga LQ, Teixeira MM. O verde da economia no campo: desafios à pesquisa e às políticas públicas para a promoção da saúde no avanço da modernização agrícola. Cien Saude Colet 2012; 17(6):1533-1542.

10. Funtowicz S, Ravetz J. Ciência pós-normal e comunidades ampliadas de pares face aos desafios ambientais. Hist. cienc. saude-Manguinhos 1997; 4(2):219-230.

11. Esteban MPS. Pesquisa qualitativa em educação: fundamentos e tradição. Porto Alegre: AMGH; 2010.

12. Gatti BA. Grupo Focal na Pesquisa em Ciências Sociais e Humanas. Brasília: Liber Livro Editora; 2005.

13. Minayo MCS. O desafio do conhecimento: pesquisa qua-

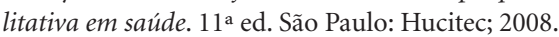

14. Thompson JB. Ideologia e cultura moderna: teoria social e crítica na era dos meios de comunicação de massa. $8^{\text {a }}$ ed. Rio de Janeiro: Editora Vozes; 2009.

15. Ferreira MJM, Alencar GP, Rigotto RM. Materialismo Histórico e Hermenêutica de Profundidade: as aproximações para a compreensão da sociedade do capital. In: Anais do IV Congresso Ibero-americano de Pesquisa Qualitativa; 2010; Fortaleza.

16. Pinto MJ. Comunicação e Discurso: introdução à Análise de Discurso. São Paulo: Hacker Editores; 1999.

17. Brasil. Ministério da Saúde (MS). Conselho Nacional de Saúde. Resolução no 196 de 10 de outubro de 1996. Diretrizes e Normas Regulamentadoras de Pesquisas Envolvendo Seres Humanos. Diário Oficial da União 1996; 16 out.

18. Ferreira MJM. Contribuições Epistemológicas/Metodológicas para o fortalecimento de uma (Cons) ciência emancipadora [dissertação]. Fortaleza: Universidade Federal do Ceará; 2012.

19. Breilh J. Epidemiologia Crítica: ciência emancipadora e interculturalidade. Rio de Janeiro: Editora Fiocruz; 2006.
20. Santos BS. Um discurso sobre as Ciências. $7^{\text {a }}$ ed. São Paulo: Cortez; 2010.

21. Rigotto RM, Ellery AEL. Caminhos na produção do conhecimento: cuidados, incertezas e criação. In: Rigotto RM, organizador. Agrotóxicos, trabalho e saúde: vulnerabilidade e resistência no contexto da modernização agrícola no Baixo Jaguaribe/CE. Fortaleza: Edições UFC; 2011. p. 71-110.

22. Bourdieu P. O poder simbólico. $14^{\text {a }}$ ed. Rio de Janeiro: Bertrand Brasil; 2010.

23. Porto MF, Finamore R. Riscos, saúde e justiça ambiental: o protagonismo das populações atingidas na produção de conhecimento. Cien Saude Colet 2012; 17(6):1493-1501.

24. Bidwell D. Is Community-Based Participatory Research Postnormal Science? Science, Technology \& Human Values 2009; 34(6):741-761.

25. Fischer F. Technological deliberation in a democratic society: the case for participatory inquiry. Science and Public Policy 1999; 26(5):294-302.

26. Santos BS. Renovar a teoria crítica e reiventar a emancipação social. São Paulo: Boitempo; 2007.

27. Santos BS. A gramática do tempo: para uma nova cultura política. $2^{\mathrm{a}}$ ed. São Paulo: Editora Cortez; 2008.

28. Freire P. Extensão ou Comunicação? 7a ed. Rio de Janeiro: Paz e Terra; 1983.

29. Araújo IS. Educação e Saúde. In: Martins, CM, Stauffer, $\mathrm{AB}$, organizadores. Educação Profissional e Docência em Saúde: a formação e o trabalho do agente comunitário de saúde. Rio de Janeiro: EPSJV; 2007. p. 101-124.

30. Brasil. Constituição da República Federativa do Brasil de 1988. Diário Oficial da União 1988; 5 out.

31. Brasil. Lei n. 8.080 de 19 de Setembro de 1990. Dispõe sobre as condições para a promoção, proteção e recuperação da saúde, a organização e o funcionamento dos serviços correspondentes e dá outras providências. Diário Oficial da União 1990; 19 set.

32. Acselrad H. Cartografia social e dinâmicas territoriais: marcos para o debate. Rio de Janeiro: Universidade Federal do Rio de Janeiro, Instituto de Pesquisa e Planejamento Urbano e Regional; 2010.

33. Nussbaum RH, Hoover PP, Grossman CM, Nussbaum FD. Community-based participatory health survey of Hanford, WA, downwinders: a model for citizen empowerment. Society and Natural Resources 2004; 17(6):547-559.

34. Martinez-Alier J, Healy H, Temper L, Walter M, Rodriguez-Labajos B, Gerber JF. Between science and activism: Learning and teaching ecological economics with environmental justice organisations. Local Environment 2011; 16(1):17-36.

35. Marx K. Crítica da filosofia do direito de Hegel. $2^{\text {a }}$ ed. São Paulo: Boitempo; 2010.

36. Scherer-Warren I. A atualidade dos movimentos sociais rurais na nova ordem mundial. Motrivivência 2000; (14):33-50.

Artigo apresentado em 04/07/2014

Aprovado em 11/07/2014

Versão final apresentada em 12/07/2014 